\title{
Sistem Informasi Penilaian Kinerja Dosen Dengan Metode Extreme Programming (Studi Kasus: STMIK MDP)
}

\author{
Desy Iba Ricoida*1, Denny ${ }^{2}$, Solihin ${ }^{3}$ \\ ${ }^{1,2}$ STMIKMDP; J1.Rajawali 14, Telp: (0711) 376400 \\ ${ }^{3}$ Jurusan Sistem Informasi, STMIK MDP, Palembang \\ e-mail: *11desih@mdp.ac.id, ${ }^{2}$ solihin.santoso@gmail.com, ${ }^{3}$ deny.45@ gmail.com
}

\begin{abstract}
Abstrak
Penilaian kinerja dosen merupakan kegiatan yang dilakukan untuk mengevaluasi kinerja dari dosen dengan tujuan untuk meningkatkan kinerja dosen. Pada proses perhitungan nilai kinerja yang dilakukan oleh STMIK MDP masih bersifat semi komputerisasi yang menyebabkan perhitungan nilai memakan waktu yang cukup lama, dari sisi dosen belum adanya transparansi informasi yang menjelaskan sumber dari penilaian dan letak aspek yang kurang dari dosen tersebut. Untuk itu diperlukan Sistem Informasi Penilaian Kinerja Dosen yang memungkinkan perhitungan nilai yang cepat serta menyediakan informasi untuk monitoring kinerja dosen. Dalam pembuatan sistem ini menggunakan Metode Extreme Programmig karena sistem penilaian kinerja dosen dibutuhkan dalam waktu yang cepat semantara terdapat kebutuhan sistem yang masih berubah - ubah.. Pembuatan sistem ini dibuat dengan aplikasi pendukung yaitu, Atom dan MySQL sebagai basis datanya. Hasil dari perancangan ini adalah sistem yang dapat mengolah data kinerja dosen dengan cepat, memberikan informasi penilaian kinerja kepada kaprodi dan Pembantu Ketua 1 sehingga dapat membantu dalam pengambilan keputusan terkait pengembangan dosen.
\end{abstract}

Kata kunci-3-5 kata kunci, Algoritma A, algoritma B, kompleksitas

\begin{abstract}
Lecturer performance assessment is an activity carried out to evaluate the performance of lecturers with the aim of improving the performance of lecturers. On the process calculating assessment which is conducted by STMIK MDP it is still semi-computerized which causes the calculation of values take a long time, from lecture side there is no transparency information which explain source from calculating and the low aspect from that lecture. So it is need Lecturer performance assessment Systems that allows rapid calculation of values and provides information for monitoring lecture performance. . In making of this system, it using the Extreme Programming Methods because the assessment system of lecture performance is needed in a fast time while there are system requirements that are still changing, and for the system, we use an supporting application which is Atom and MySQL as an database. The result of design is an system that can processlecturer performance data quickly, provide performance information to lecturer and the vice director so that can help in decisionmaking related lecturer development.
\end{abstract}

Keywords-3-5 keywords, Algorithm A, Balgorithms, complexity 


\section{PENDAHULUAN}

$\mathrm{D}$ osen merupakan unsur penting dalam sistem pendidikan di sebuah perguruan tinggi dimana dosen memiliki tugas dan tanggung jawab dalam tri darma perguruan tinggi yaitu melaksanakan proses pembelajaran, melakukan kegiatan penelitian dan pengabdian kepada masyarakat [1], dosen merupakan aset bagi sebuah perguruan tinggi dimana dosen memegang peranan penting dalam menciptakan lulusan berkualitas dimana hal tersebut merupakan tujuan dari pendidikan. Hal ini menyebabkan dosen perlu diperhatikan kualitasnya dalam proses belajar mengajar dimana penilaian diperlukan untuk dapat membuat kinerja dosen menjadi lebih baik.

Proses penilaian dosen pada STMIK MDP dilakukan pada pertengahan semester dan akhir semester, penilaian diawali dari mahasiswa mengisi poling kuesioner pengajaran dosen kemudian selanjutnya data akan diproses sehingga diperoleh nilai sementara indeks kinerja dosen berdasarkan mahasiswa, akan tetapi seorang dosen tidak hanya dinilai dari sisi pengajaran saja akan tetapi juga kegiatan penelitian dan pendidikan sehingga diakhir semester juga akan dilakukan rekap data beberapa aktivitas pendukung pembelajaran, kegiatan penelitian dan pengabdian yang telah dilakukan pada semester tersebut. Semua kegiatan tersebut belum memanfaatkan sistem informasi secara terpusat dimana data - data yang ada harus dioleh kembali dengan menggunakan excel sedangkan waktu penilaian kinerja dosen sangat terbatas karena dilakukan setiap semester perkuliahan berjalan dan data indikator penilaian yang cukup banyak sehingga kebutuhan terhadap pengembangan sistem informasi penilaian kinerja dosen sangat diperlukan untuk membuat proses penilaian kinerja menjadi lebih efektif dan efisien.

Berdasarkan permasalahan tersebut, maka penulis melakukan pengembangan sistem informasi penilaian kinerja dosen dengan menggunakan model pengembangan sistem Extreme Programming [2] yaitu metode pengembangan yang mengimplementasikan metode Agile Development yang mempunyai fitur penyederhanaan proses disaat diperlukan perubahan mendadak. Untuk itu dengan mengkombinasikan metode sederhana dan proses pengembangan yang lebih responsif terhadap pengguna sistem, metode Extreme Programming akan sesuai digunakan digunakan dalam pengembangan Sistem Informasi Penilaian Kinerja Dosen pada STMIK MDP.

\section{METODE PENELITIAN}

\subsection{Metode Pengumpulan Data}

Pada penelitian ini pengumpulan data dilakukan dengan beberapa metode baik itu data primer maupun data sekunder, beberapa metode pengumpulan data yang digunakan yaitu:

a. Wawancara

Wawancara yaitu kegiatan yang dilakukan untuk mendapatkan informasi secara langsung terkait dengan objek penelitian, dengan wawancara maka akan didapatkan data primer yang kemudian akan dilakukan pengolahan kembali data tersebut untuk mendapatkan data yang lebih valid.

b. Observasi

Observasi merupakan sebuah kegiatan dimana penulis mengamati secara langsung aktivitas yang berkaitan dengan objek yang diteliti sehingga dapat melakukan identifikasi masalah secara lebih tepat, dalam hal ini adalah observasi proses penilaian kinerja dosen pada STMIK MDP

C. Dokumentasi

Melihat dokumentasi kegiatan atau catatan kegiatan penilaian kinerja dosen yang sudah dilakukan sebelumnya baik dalam bentuk cetak maupun file komputer. 
d. Study Pustaka

Study pustaka merupakan proses kegiatan mengumpulkan referensi pendukung baik melalui buku, jurnal serta sumber - sumber lainnya yang terkait dengan objek yang diteliti.

Pada penelitian ini penulis menggunakan pendekatan metode pengembangan sistem yaitu Extreme Programming, adapun tahapan -tahapan dalam metode ini dapat terlihar pada gambar 1.

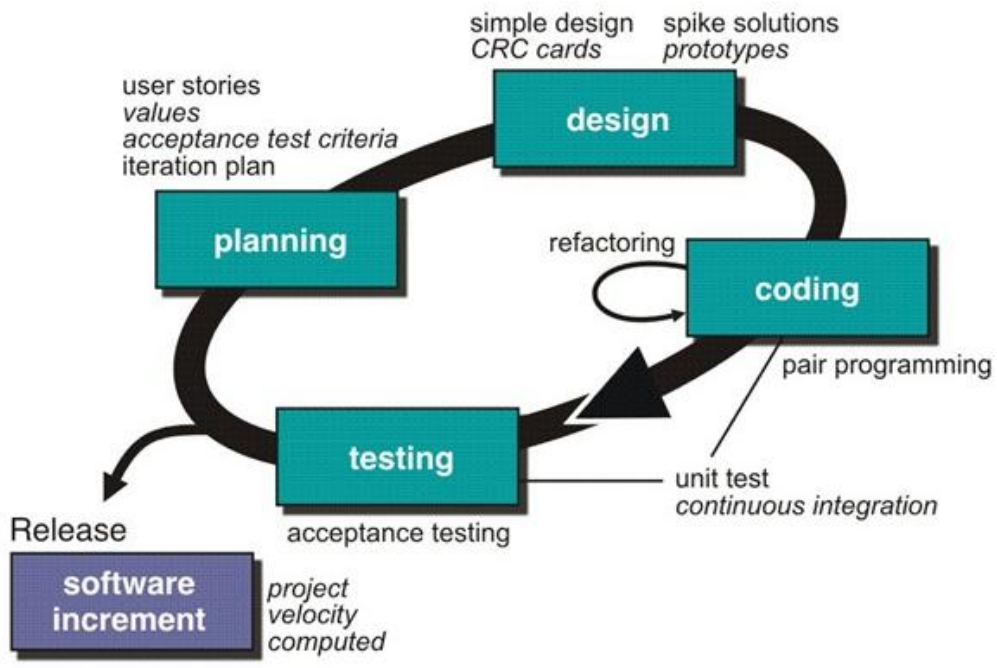

Sumber: Pressman [3]

Gambar 1. Siklus Hidup Extreme Programming

\subsection{Metode Pengembangan Sistem}

Tahapan - tahapan yang dilakukan dalam pengembangan sistem informasi penilaian kinerja dosen dengan menggunakan model Extreme Programming [4] sebagai berikut:

a. Perencanaan, pada tahapan ini peneliti melakukan perencanaan berdasarkan requirements user dimana dilakukan pengaturan prioritas terhadap permintaan user berdasarkan skala prioritas dan waktu pembangunan sistemnya. Pada perencanaan ini akan dilakukan pengecekan kembali dengan mempertimbangkan resiko yang dihasilkan.

b. Desain, pada tahapan desain dilakukan proses iterasi selama pembangunan dimana proses analisis dan desain akan menghasilkan beberapa UML antara lain use case diagram, activity diagram, sequence diagram dan class diagram. Pada tahapan ini sudah membangun prototype awal sebagai gambaran sistem yang akan dibangun.

c. Coding (pengkodean sistem), dalam tahap ini prototype yang sudah disepakati akan diterjemahkan kedalam pemrograman dengan menggunakan PHP, HTML, Atom untuk tampilan antarmuka dan database MySQL.

d. Pengujian sistem, sistem selesai dibangun dan selanjutnya akan dilakukan proses pengujian sistem oleh pengguna sistem.

\subsection{Sistem Informasi}

Sistem informasi meliputi beberapa komponen yang saling berhubungan antara, manusia, komputer, teknologi, dan prosedur, kemudian data diproses menjadi informasi, dan digunakan untuk mencapai suatu sasaran atau tujuan [5].

\section{$2.4 \quad P H P$}

PHP (akronim dari Hypertext Preprocessor) adalah bahasa pemograman intrepeter yaitu proses penerjemahan baris kode sumber menjadi kode mesin yang dimengerti oleh komputer secara langsung pada saat baris kode dijalankan sehingga web menjadi dinamis [6]. PHP yang

Ricoida, et, al (Sistem Informasi Penilaian Kinerja Dosen Dengan Metode Extreme Programming (Studi Kasus: 
merupakan bahasa pemrograman berbasis web yang memiliki kemampuan untuk memproses data dinamis.

\section{2. $5 \quad M y S Q L$}

Merupakan software yang tergolong database server dan bersifat Open Source. Open Source menyatakan bahwa software ini dilengkapi dengan source code (kode yang dipakai untuk membuat $M y S Q L$ ), selain itu tentu saja bentuk executable-nya atau kode yang dapat dijalankan secara langsung dalam sistem. [7]

\section{HASIL DAN PEMBAHASAN}

Berdasarkan hasil analisa tentang kebutuhan sistem oleh pengguna, maka kebutuhan sistem tersebut diidentifikasikan melalui rancangan sistem dengan menggunakan diagram Unified Model Language (UML) sebagai berikut:

\subsection{Rancangan Use Case Diagram}

Use Case merupakan pemodelan untuk menggambarkan kelakuan sistem yang akan dibuat [7]. Use Case Diagram dirancang untuk menjelaskan interaksi apa saja yang dapat dilakukan user terhadap aplikasi seperti pada gambar 2.

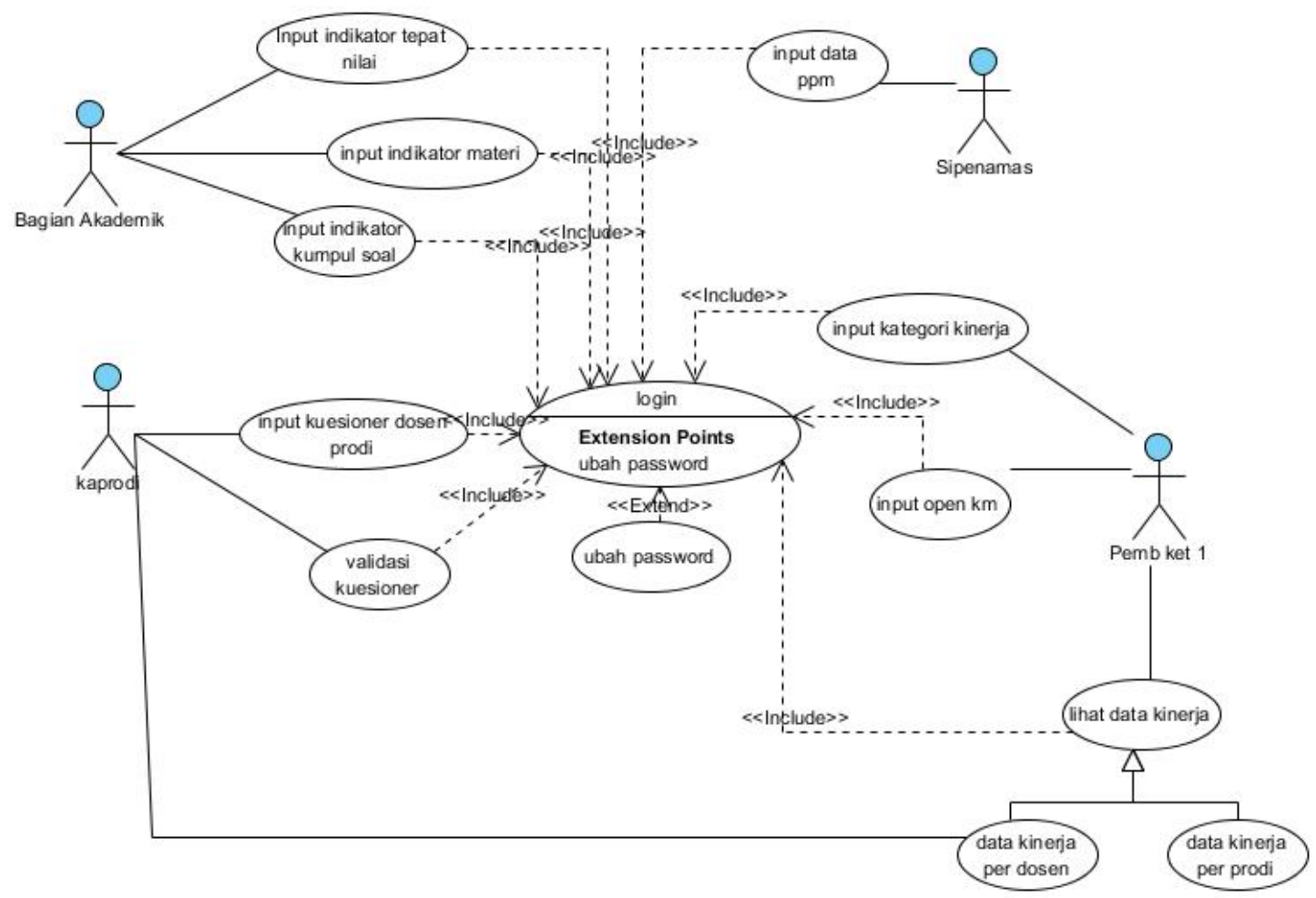

Gambar 2. Use Case Diagram

\subsection{Rancangan Activity Diagram}

Activity diagram menggambarkan workflow (aliran kerja) atau aktivitas dari sebuah sistem atau proses bisnis atau menu yang ada pada perangkat lunak [7]. Gambar activity diagram input kuesioner yang dilakukan oleh kaprodi dapat dilihat pada pada gambar 3 


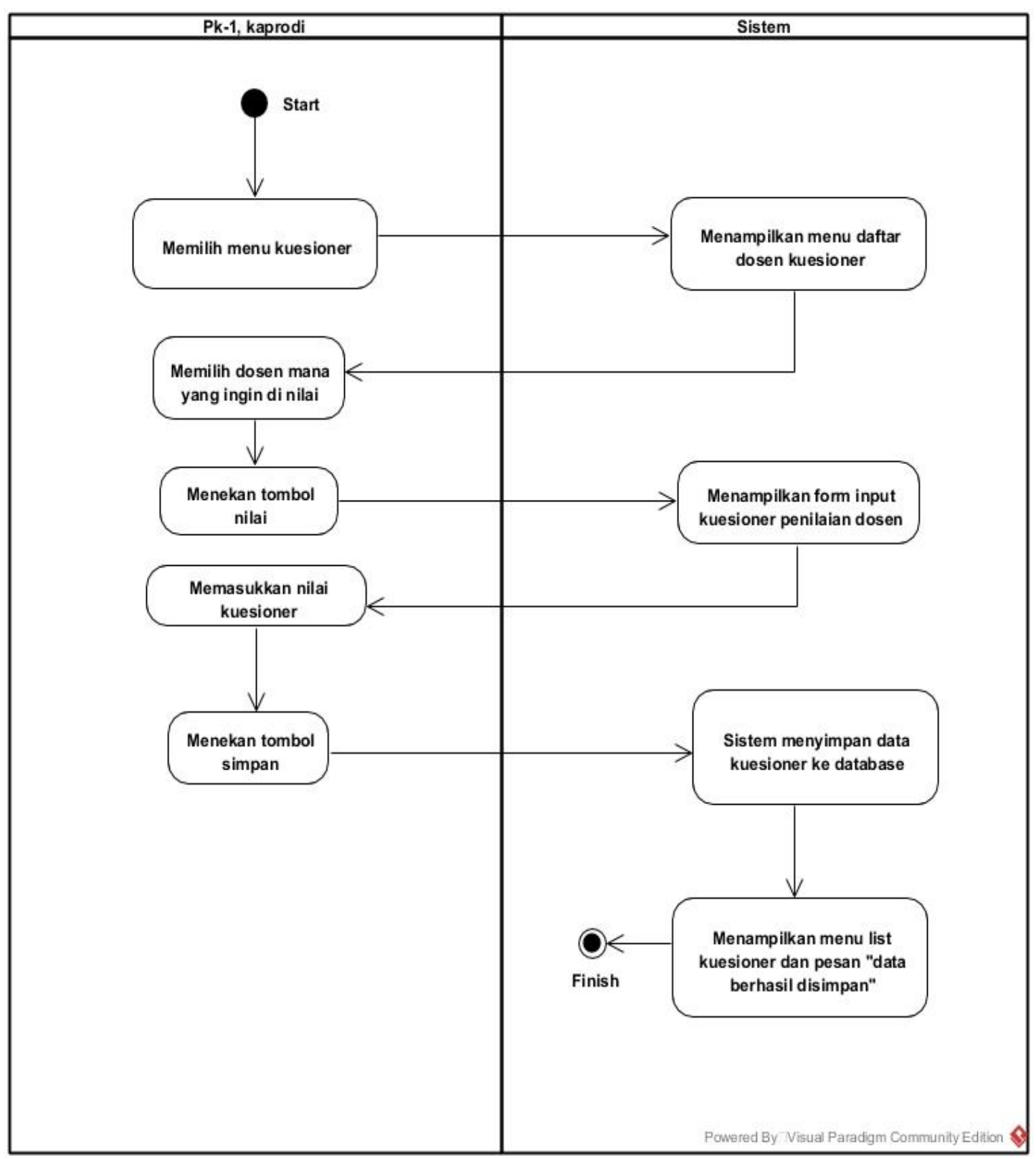

Gambar 3. Activity Diagram Input Kuesioner

Pada gambar 4 menunjukkan urutan aktivitas yang dilakukan oleh actor Pembantu Ketua 1 (PK-1) dan Kaprodi untuk melihat kinerja dosen per prodi. 


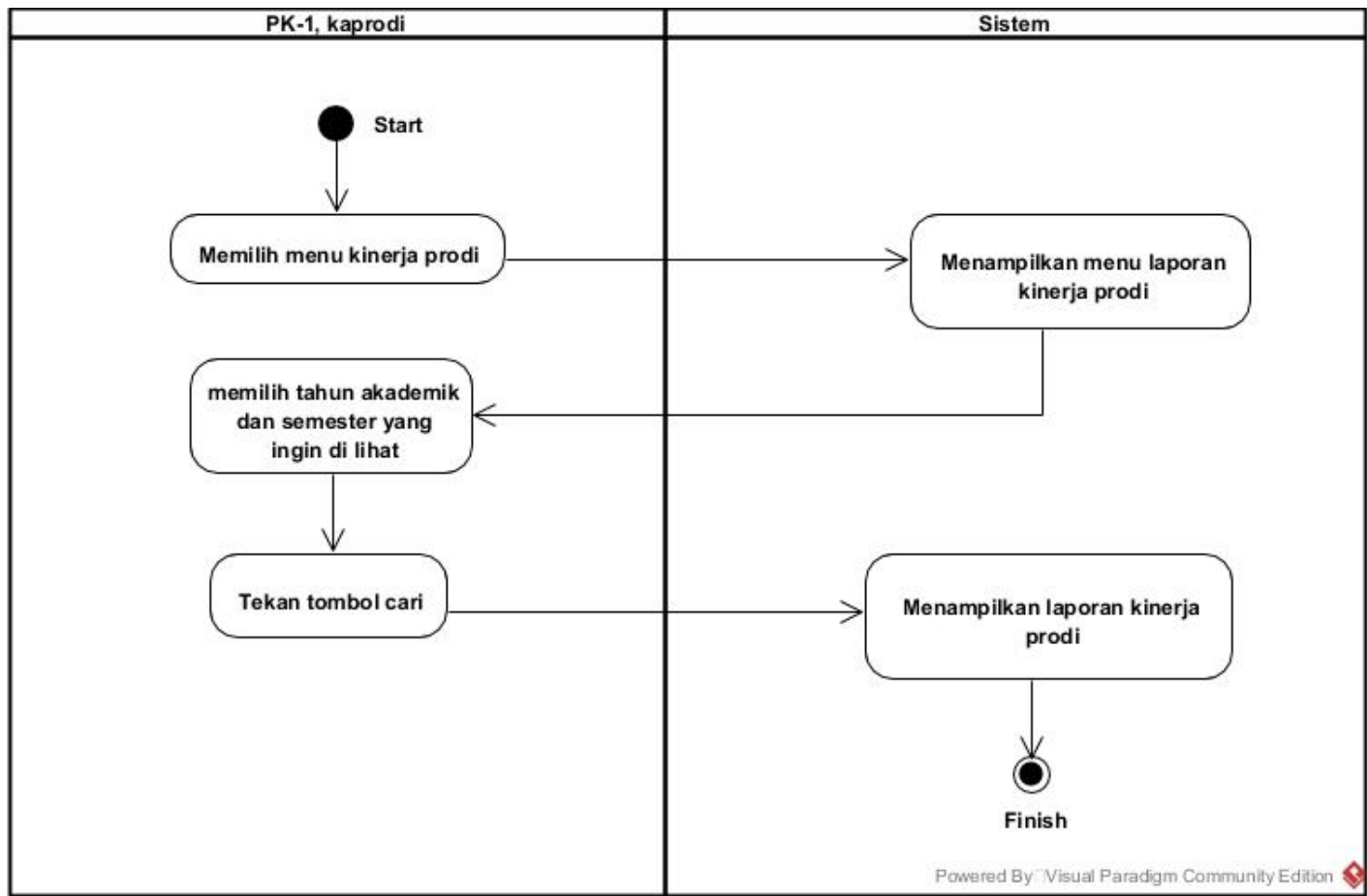

Gambar 4. Activity Diagram Lihat Kinerja Prodi

\subsection{Rancangan Sequence Diagram}

Diagram sekuen menggambarkan perilaku obyek pada use case dengan menjelaskan lifetime dari obyek dan message yang dikirim dan diterima antar obyek. Oleh karena itu untuk menggambarkan diagram sekuen perlu diketahui obyek-obyek apa saja yang terlibat dan metode yang dimiliki kelas yang diinstansiasi menjadi obyek tersebut.

a. Diagram Sekuen Input Kuesioner

Berikut ini merupakan diagram sekuen yang menggambarkan saat pengguna melakukan proses penambahan nilai kuesioner.

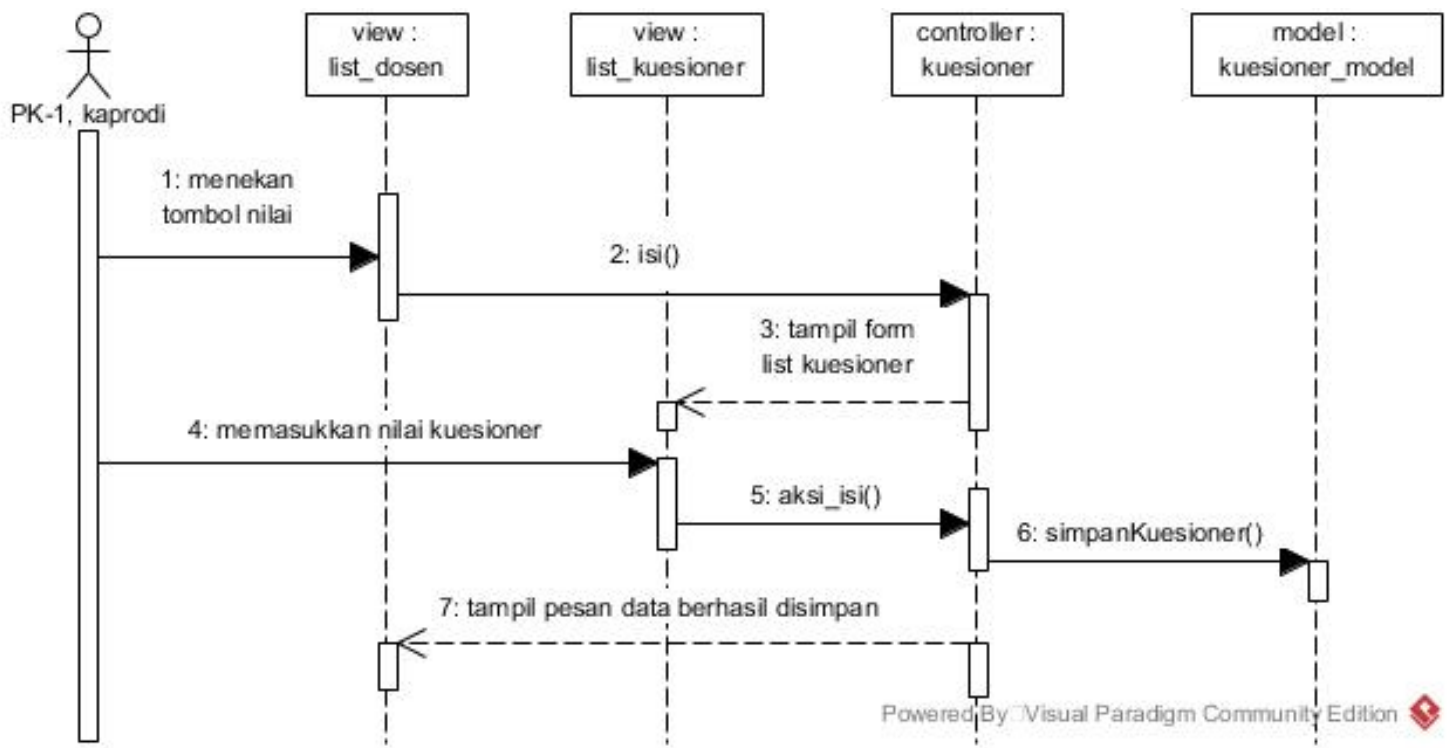

Gambar 5.Sequence Diagram Input Kuesioner

Ricoida, et, al (Sistem Informasi Penilaian Kinerja Dosen Dengan Metode Extreme Programming (Studi Kasus: 
b. Diagram Sekuen Lihat Kinerja per prodi

Berikut ini merupakan diagram sekuen yang menggambarkan saat pengguna melakukan proses melihat data kinerja prodi.

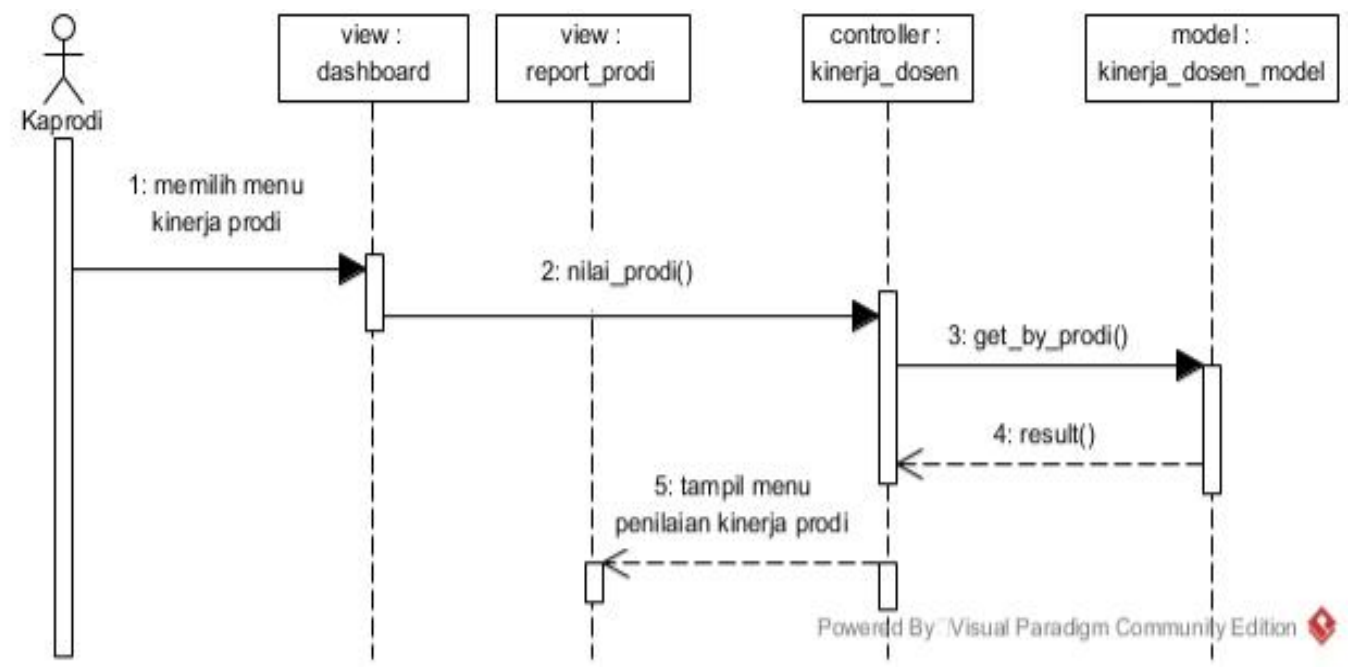

Gambar 6. Sequence Diagram Lihat Kinerja Prodi

3.4 Tampilan Halaman Penilaian Kinerja Dosen

a. Tampilan menu Login

Berikut ini merupakan tampilan menu login, sebelum masuk ke halaman web di perlukan login terlebih dahulu dengan memasukkan username dan password seperti yang ditunjukkan oleh gambar.

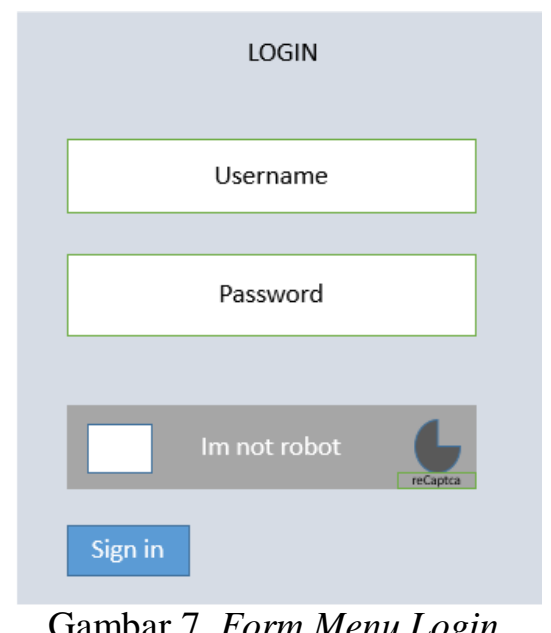

Gambar 7. Form Menu Login

b. Tampilan menu Kuesioner dan Input Kuesioner

Berikut ini merupakan tampilan menu kuesioner, pada menu kuesioner terdapat tabel data kuesioner yang dilengkapi tombol nilai, view dan update. 


\begin{tabular}{|c|c|c|c|c|c|c|}
\hline NO & Kode Dosen & $\begin{array}{c}\text { Nama } \\
\text { Dosen }\end{array}$ & Program Studi & Status & Aksi \\
\hline 1 & 999999 & $x x x x x x$ & $x x x x x x x$ & $\begin{array}{c}\text { sudah } \\
\text { ointai }\end{array}$ & View & Update \\
\hline 2 & 999999 & xxxxxxxxxxx & xxxxxxxxxxxxxxxx & $\begin{array}{c}\text { Belum } \\
\text { Dinlai }\end{array}$ & Nilai \\
\hline
\end{tabular}

Gambar 8. Form Mеnu Kuesioner

Adapun pada gambar 9 merupakan tampilan forminput kuesioner, pada form input kuesioner data yang diinput berupa nilai kompetensi dari dosen. Form ini dilengkapi tombol simpan.

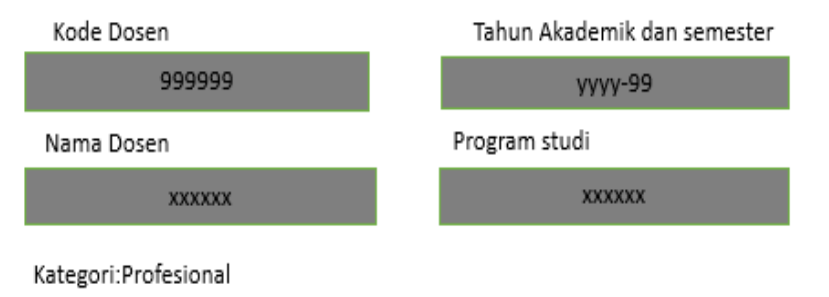

\begin{tabular}{|c|c|r|}
\hline No & Nama Kompetensi & Nilai \\
\hline 1 & $\operatorname{xxxxxxxxxxx}$ & $\square$ \\
\hline
\end{tabular}

\begin{tabular}{|c|c|c|}
\hline \multicolumn{2}{|c|}{ Kategori:Padagogik } \\
\hline No & Nama Kompetensi & Nilai \\
\hline 2 & $\operatorname{xxxxxxxxxxxxx}$ & \\
\hline
\end{tabular}

Kategori:Kepribadian
\begin{tabular}{|c|c|r|}
\hline No & Nama Kompetensi & Nilai \\
\hline 3 & xxxxxxxxxxxxxx & \\
\hline \multicolumn{2}{|c|}{ Kategori:Sosial } \\
\hline No & Nama Kompetensi & Nilai \\
\hline 4 & xxxxxxxxxxxxxxxxxxx & \\
\hline
\end{tabular}

Gambar 9. Tampilan Form Input kuesioner

c. Tampilan Menu Lihat Kinerja Per Prodi

Berikut ini merupakan tampilan menu laporan kinerja prodi, pada menu laporan kinerja prodi terdapat tabel data kinerja prodi yang dapat di lihat berdasarkan tahun akademik dan semester. Menu laporan kinerja prodi dilengkapi dengan tombol cari dan cetak seperti pada gambar 10. 


\begin{tabular}{|c|c|c|c|c|c|c|c|c|c|c|}
\hline \multicolumn{2}{|c|}{ Tahun Akademik } & & \multicolumn{2}{|l|}{ Semester } & \multirow[b]{2}{*}{ Cari } & \multirow[b]{2}{*}{ tak } & & & & \\
\hline yyyy & yyy $\mathrm{V}$ & & $x x x x x$ & V & & & & & & \\
\hline No & $\begin{array}{l}\text { Kode } \\
\text { Dosen }\end{array}$ & $\begin{array}{l}\text { Nama } \\
\text { Dosen }\end{array}$ & $\begin{array}{c}\text { Penilaian } \\
\text { Atasan }\end{array}$ & IKD & $\begin{array}{c}\text { Kumpul Soal } \\
\text { dan Nilai }\end{array}$ & Pertemuan & $\begin{array}{l}\text { Upload } \\
\text { Materi }\end{array}$ & PPM & $\begin{array}{l}\text { Upload } \\
\text { Open KM }\end{array}$ & Total \\
\hline 1 & 999999 & $x x x x x x x$ & 99 & 99 & 99 & 99 & 99 & 99 & 99 & 999 \\
\hline 2 & 999999 & Xxxxxxx & 99 & 99 & 99 & 99 & 99 & 99 & 99 & 999 \\
\hline 2 & 999999 & $X_{x x x x x x}$ & 99 & 99 & 99 & 99 & 99 & 99 & 99 & 999 \\
\hline
\end{tabular}

Gambar10. Tampilan Menu Laporan Kinerja Prodi

\section{KESIMPULAN}

Kesimpulan yang didapat hasil pengembangan sistem informasi penilaian kinerja dosen adalah sebagai berikut:

1. Proses perhitungan penilaian indikator kinerja dosen menjadi lebih efisien karena setiap komponen penilaian dihitung secara komputerisasi.

2. Kaprodi dan Pembantu Ketua 1 Bidang Akademik dapat lebih mudah melakukan monitoring penilaian kinerja dosen per prodi sehingga dapat digunakan untuk menentukan strategi dalam pengembangan kinerja dosen.

3. Pemilihan Metode Extreme Programming sebagai metode pengembangan sistem dapat mempersingkat waktu pengembangan karena dengan metode ini telah ditentukan skala prioritas pengerjaan fitur sistem serta pengerjaan sesuai dengan waktu yang telah disepakati.

\section{SARAN}

Adapun saran untuk pengembangan sistem informasi penilaian kinerja dosen lebih lanjut yaitu:

1. Sistem Informasi penilaian kinerja dosen ini dapat memiliki fungsi back up secara otomatis.

2. Pengembangan fitur sistem kedepan sebaiknya memiliki perencanaan waktu yang cukup sehingga dapat lebih maksimal pengembangan fitur sistem penilaian kinerja dosen.

\section{DAFTAR PUSTAKA}

[1] Undang-undang Republik Indonesia No. 14 Tahun 2005 Tentang Guru dan Dosen

[2] Harison, Roby Faisal. 2017, Aplikasi Penilaian Kinerja Dosen pada Proses Belajar Mengajar Berbasis Web: Studi Kasus di Badan Penjaminan Mutu Internal Institut Teknologi Padang, Jurnal Teknologi dan Sistem Komputer, 5(2), 89-93, https://jtsiskom.undip.ac.id/index.php/jtsiskom. 
[3] Pressman, R. 2005, Software Engineering: A Practitioner's Approach 6th Edition, McGraw Hill, New York.

[4] Wahyudin, Nur Komariah. 2001, Rancang Bangun Sistem Akademik Berbasis Web Menggunakan Metode Extreme Programming, Seminar Nasional dan Inovasi (SNIT) 2018, Jakarta, 25 Juli 2018, McGraw Hill, New York.

[5] Sibero, A. F. 2011, Kitab Suci Web Programing, Media Kom, Jakarta.

[6] Kadir, Abdul. 2009, From Zero to Pro Membuat Aplikasi Web PHP + Database MySQL, Andi, Yogyakarta.

[7] A.S, Rosa dan M. Shalahuddin. 2013, Rekayasa Perangkat Lunak Terstruktur dan Berorientasi Objek, Informatika, Bandung. 